\title{
Perhaps its Time to Move on to Individually Tailored and Focused Treatment in the Aged Population
}

\author{
Rajesh Chauhan ${ }^{*}$, Ajay Kumar Singh Parihar and Shruti Chauhan
}

Family Healthcare Centre, India

*Corresponding author: Rajesh Chauhan, Family Healthcare Centre, 154 / 6-B, Avas Vikas Colony Sikandra, AGRA- 282007, India, Tel: +91-9760021192; E-mail: drrajeshchauhan@gmail.com

Rec Date: May 06, 2016, Acc Date: May 31, 2016, Pub Date: Jun 03, 2016

Copyright: ( 2016 Chauhan R, et al. This is an open-access article distributed under the terms of the Creative Commons Attribution License, which permits unrestricted use, distribution, and reproduction in any medium, provided the original author and source are credited

\section{Commentary}

Geriatric population is increasing by the day, and what's more worrisome are the accompanying morbidities with aging. Multimorbidity seems to be a common presentation in the aged which usually leads to polypharmacy, and that again is a growing concern. As we had said many years ago, it's not that the aged are looking forward to increased longitivity [1]. They are probably more interested to remain fit enough so as to carry on with their daily chores, as was opined by us [1]. Since one size will never fit all, therefore, based on the multi-morbidities an individually tailored approach may perhaps be more helpful. With the decline of the bodily functions and physiology as we age, there can be so many different medical and physical disabilities. There can be all sorts of combinations of problems, some apparent and many unapparent, which will require all the skills and expertise from a Geriatrician or from the treating physician. May be a revisit and a fresh look at all the problems from head to toe might help in pruning down the list of diagnosis, which in turn could also help to curtail inadvertent polypharmacy.

We really need to listen well and with empathy to what our elderly patient have to say about their problems. Besides the stress and burden of medical problems, there could be some other associated socioeconomic stresses, caregiver stress, their outstretched patience and hope, etc, which we need to understand. There can be so many combinations in twos and threes or maybe more, with each weighing down the other. Both figuratively and literally, we must try our best to take care of their problems so that they do not lose their heart. In many cases we may be able to tackle some of the morbidities, thereby leaving a patient slightly better off and with lessened morbidities. In this context maybe some of our innovative approaches that we had stumbled upon, and had presented to the world, may be of some help [2]. We would like to admit that these innovative techniques have not been scrutinized or peer reviewed so far by the medical and scientific community. As far as speculations go, all this was already speculated by us some years ago in our book [2], where a complete chapter has been dedicated towards this end. But then all this needs to be followed up by meaningful research by global medical and scientific community if we really are intent to improve upon the management of medical problems faced by the elderly population. Perhaps it's time to move on to individually tailored and focused treatment in the aged population.

Old age cannot be reversed, and this would be accompanied by changes like graying of hair, decreasing eye sight and hearing, etc. We may be wrong, but then certain 'accepted' trends are possibly based on convenience, rather on scientific correctness. For example, it is known that loud noise which destroys the 'hair cells' is one of the cause for the age-related hearing loss (presbycusis), and for the remediation we conveniently have hearing aids and cochlear implants, which are amplification devices and subject the same patient to louder noise very close to ears, or within the ears, thereby essentially posing a greater challenge to the remaining population of hair cells. We are of the view that restoration of hearing by a hearing aid could be a matter of convenience and expediency. To us this would remain scientifically incorrect, since we should now try to save the remaining hair cell population as best as we can, instead of subjecting the remaining hair cells to louder noise through amplification device that is placed so close to the ear or maybe within it, thereby ensuring their rapid destruction. This we have already discussed along disclosing our new innovative technique in our book that reverses the age-related hearing loss, and can restore back normal hearing [3]. Likewise we have been having a different view for some more chronic medical problems, and we have tried explaining them some time ago [2].

All that we would like to say now is that all our innovative techniques could possibly turn out to be quite helpful to the elderly patients, and this we can presume from whatever positive experiences that we have gained so far. But before that certainly much more collaborative global research and controlled clinical trials are needed on all of our innovative techniques that we had stumbled upon serendipitously, that are thoroughly scrutinized and peer reviewed [2]. In fact, talking about innovative thinking and approach, we can possibly start managing chronic condition like essential hypertension in a much simpler and meaningful manner. In this context, we had presented our "Kalhore Technique" last year at an international conference [4], but like all other of our innovative medical techniques, this technique too requires a thorough research by global community, as we had already suggested a long time ago [4]. For various stated and unstated reasons, any further research has been way beyond our scope despite our best efforts [2-4].

It is reiterated that all of our innovations have happened serendipitously. We certainly would have loved to get some much needed help, support and encouragement. In the absence of all this, we have done what we could from our own resources basically coming from the humble pension of the prime author. Now from here on we feel that it is basically for the world's medical and scientific community, and the geriatric population, to rethink on the plusses and minuses of the current trend of management that everyone has become so familiar with. At the same time we are of the opinion that meaningful deliberations are needed if we are genuinely interested to change the approach and to bring about positive changes in the management of the elderly population.

Perhaps by moving on to individually tailored, innovative and focused treatment in the aged population, the results can be highly gratifying, and could ease out some of the morbidities in geriatric patients. In the figure below (Figure 1), we have taken the example of an overburdened ship and for understanding purposes have equated it 
with an elderly facing the burden of multi-morbidities. This overburdened ship can topple or sink if not provided some immediate help and respite. Likewise is the case with an elderly who might be getting overwhelmed bearing his or her own load of multi-morbidities. We have tried to show the effects of our innovative medical techniques in a simple fashion that is easy to comprehend (Figures 1 and 2), but this can come about only if the global medical and scientific community happens to find even an iota of substance in what we have so far presumed.

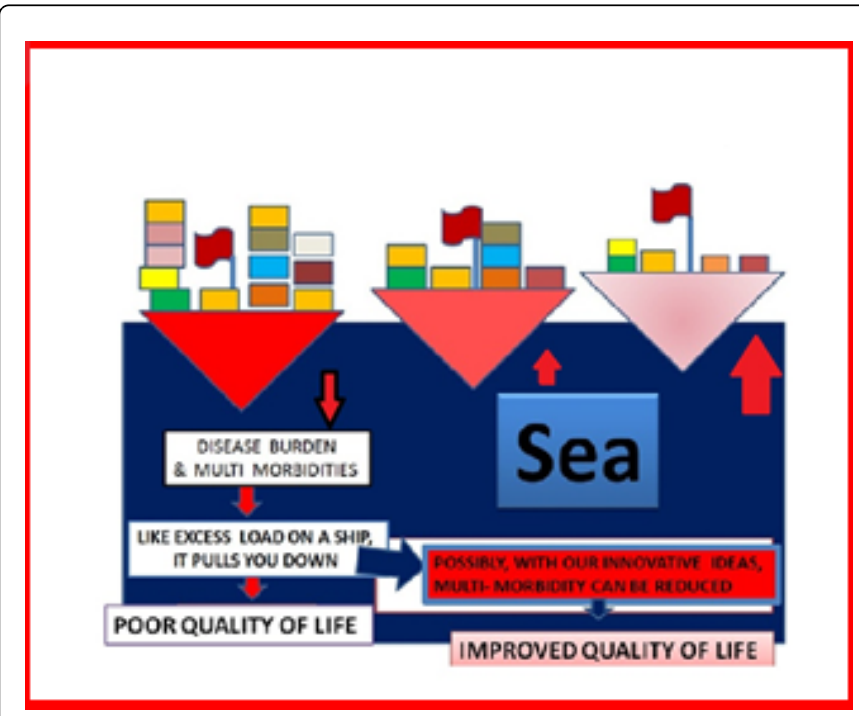

Figure 1: Patient compared to a sinking ship, due to overloaded with multi-morbidities.

Our concern and efforts should be redirected towards their ADL (activities of daily living) and IADL (instrumental activities of daily living), and we must try to improve them. Our innovative techniques that we have described in our book titled, "Innovative medical techniques showcased at international conferences", were accidental discoveries [2].

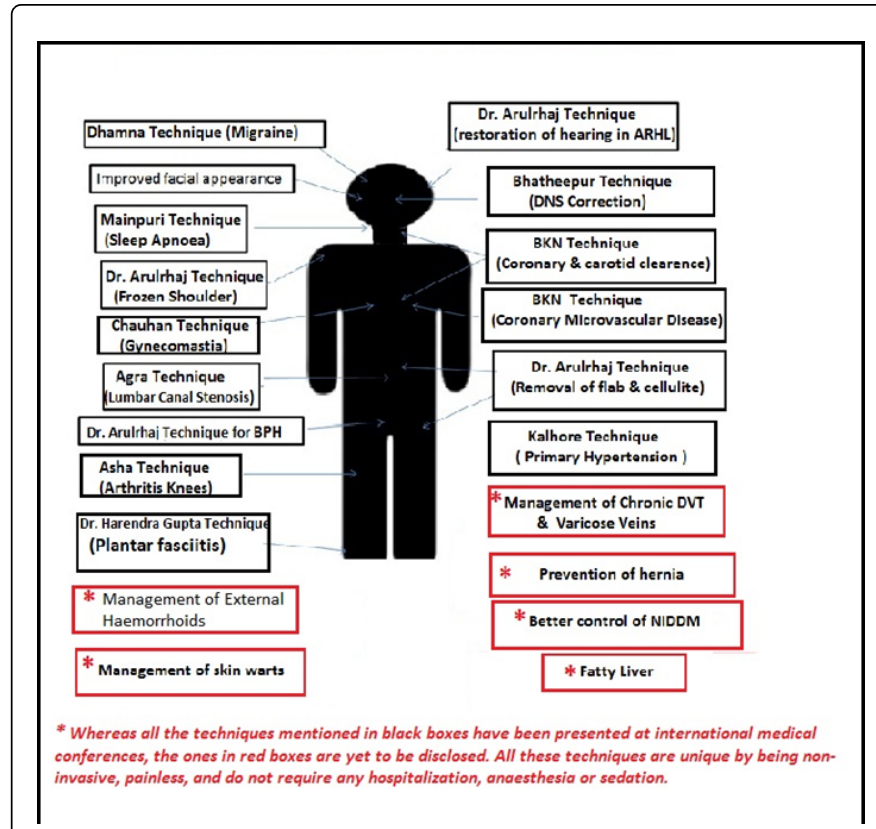

Figure 2: Adapted from the book titled "innovative medical techniques showcased at international conferences".

Nevertheless, all of these do have the potential to be quite beneficial for geriatric patients, and can bring down on the morbidity levels, expenses, and polypharmacy as well. Our innovative techniques can be quite helpful to the poor who can ill afford the presently available management which is oftentimes way beyond their means, and can also help those patients who are unfit for anesthesia or surgery, or those who have long waiting periods. We would like the global medical and scientific community to improve all of our innovative techniques, add finesse, so as to make them absolutely safe, more precise and easy. Having repeatedly seen the positive results of our innovative medical techniques, we indeed are quite optimistic and are of the view that the quality of life can be improved, but only if we are more focused and practice individualized treatment.

\section{References}

1. Chauhan R, Singh AK, Kushwah P (2005) Who needs health care? Old people are faced with dilemma as families disintegrate. BMJ 330: 1331-1332.

2. Chauhan R, Chauhan S, Parihar AKS (2014) Our vision for the future: rejuvenation and 'overhauling' to the extent possible within a week, Innovative Medical Techniques Showcased at International Conferences. Lambert Academic Publishing, UK.

3. Chauhan R, Chauhan S, Parihar AKS (2014) Restoration of natural hearing in age-related hearing loss by 'Dr. Arulrhaj Technique.' In: Innovative Medical Techniques Showcased at International Conferences. LAP Lambert Academic Publishing, UK.

4. Chauhan R, Chauhan S, Parihar AKS (2015) Kalhore Technique. Novel non-drug adjunct therapy for hypertension, Proceedings of the IMA's international conference ICON 2015.
This article was originally published in a special issue, entitled: "Elderely Health Care", Edited by Wadie I. Najm 